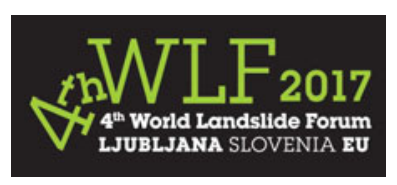

\title{
World Federation of Engineering Organizations (WFEO)_-World Federation of Engineering Organizations Activities in Disaster Risk Reduction
}

\author{
Kenichi Tsukahara
}

\begin{abstract}
In the Sendai Framework, the importance of coordination mechanisms within and across sectors and with relevant stakeholders at all levels is stressed. Engineers are working for disaster risk management in the public sector, private sector, and community. Thus, the World Federation of Engineering Organizations (WFEO), which represents the engineering profession worldwide, should take an important role in achieving the goals of the Sendai Framework. This paper explains what WFEO and WFEO's committee on disaster risk management (CDRM) are, and activities of CDRM in achieving goals of the Sendai Framework.
\end{abstract}

Keywords

Sendai framework - Multisectoral/transdisciplinary approach - Implementation of DRR

\section{Outline and Mission of the World Federation of Engineering Organizations}

\section{Outline}

The World Federation of Engineering Organizations (WFEO) is an international, non-governmental organization representing the engineering profession worldwide. On March 4th, 1968, representatives of 50 scientific and technical associations from all over the world met under the auspices of the United Nations Educational, Scientific and Cultural Organization (UNESCO) in Paris to establish WFEO, whose charter as an international, non-governmental organization is to unite multidisciplinary engineering associations throughout the world. WFEO encourages all of its national and international members to contribute to global efforts to establish a sustainable, equitable and peaceful world by providing an international perspective and enabling mechanisms:

K. Tsukahara $(\bowtie)$

Secretary of Committee on Disaster Risk Management of World Federation of Engineering Organizations, Paris, France

e-mail: tsukahara@doc.kyushu-u.ac.jp
(1) To provide information and leadership to the engineering profession on issues of concern to the public or the profession.

(2) To serve society and to be recognized, by national and international organizations and the public, as a respected and valuable source of advice and guidance on the policies, interests and concerns that relate engineering and technology to the human and natural environment.

(3) To make information on engineering available to the countries of the world and to facilitate communication between its member nations.

(4) To foster peace, socioeconomic security and sustainable development among all countries of the world, through the proper application of technology.

(5) To facilitate relationships between governments, business and people by adding an engineering dimension to discussions on policies and investment (Fig. 1).

\section{Mission of the WFEO}

WFEO is the internationally recognized and chosen leader of the engineering profession and cooperates with national and 
Fig. 1 WFEO general assembly at Kyoto in 2015

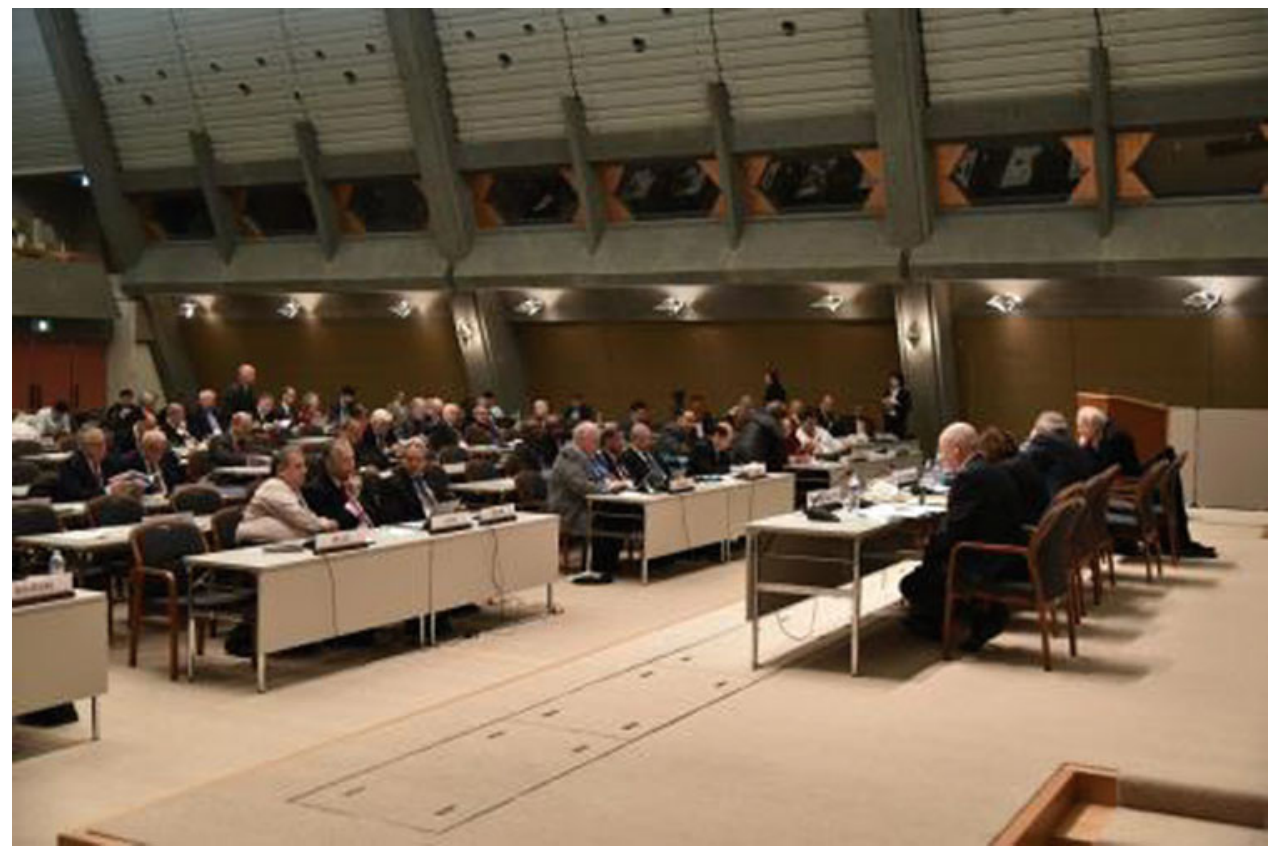

other international professional institutions in being the lead profession in developing and applying engineering to constructively resolve international and national issues for the benefit of humanity. Based on this mission, WFEO's mission is described as follows:

(1) To represent the engineering profession internationally, providing the collective wisdom and leadership of the profession to assist national agencies choose appropriate policy options that address the most critical issues affecting countries of the world.

(2) To enhance the practice of engineering - to make information on engineering available to the countries of the world and to facilitate communication between its member nations about the world's best practices in key engineering activities.

(3) To foster socio-economic security and sustainable development and poverty alleviation among all countries of the world, through the proper application of technology.

(4) To serve society and to be recognized by national and international organizations and the public, as a respected and valuable source of advice and guidance on the policies, interests and concerns that relate engineering and technology to the human and natural environment.

(5) To cooperate with funding agencies such as development banks.

(6) To encourage public-private partnerships by including the engineering dimension.

(7) To address the issue of what public policies need to be implemented.

\section{Committee on Disaster Risk Management of WFEO}

\section{Background of CDRM}

In general, disasters are caused by natural hazards and/or manmade incidents. The disasters referred to hereafter arise as consequence of natural hazards such as earthquakes, tsunamis, floods, droughts, cyclones, typhoons or hurricanes, landslides, forest fires, and volcanic eruptions; they are also caused by manmade incidents such as industrial accidents, power cuts, and air-pollution. These disasters affect human lives directly or indirectly, while having an impact on human societies and natural environments.

There are various phases of disaster risk management (DRM) - from identifying, evaluating, mitigating, and managing disaster risks to adapting to climate change. Risk management includes disaster preparedness programs, disaster response, disaster damage assessment, reconstruction, and rehabilitation. Note that there are various types of damage, including direct and indirect damage, physical and non-physical damage; monetary and non-monetary damages; short-term, mid-term and long-term damage; as well as economic damage and the loss of human life. Hence, approaches to mitigation and adaptation activities should be evaluated for each disaster in cost-benefit terms.

Based on this understanding, establishment of the Committee on Disaster Risk Management of WFEO (CDRM) as a standing committee was approved by the General Council of WFEO on November 2009. Dr. Yumio Ishii was appointed as the founding president of WFEO-CDRM. 
Dr. Ishii served as the president of CDRM until 2013, and Dr. Toshimitsu Komatsu was appointed as the second president from 2013.

CDRM helps to develop and implement advanced expertise and practical training to achieve societies that are strong and resilient in the face of disaster, while mobilizing every available resource to reduce disaster risks and potential damage. The extent and level of damage and risk should be discussed and determined within the CDRM. The definition of "risk" is not necessarily restricted to likely dangers. "Risk" also has a broader meaning, related to the mitigation of and adaptation to situations that result from disasters.

It is also important to consider not only single hazards or risks, but also the interrelation between multiple hazards and risks. After the 2011 Tohoku earthquake and tsunami in Japan, "resilience" has also been an important key word in disaster risk management. It is particularly important to consider the role of resilience (in conjunction with disaster reduction) when considering global climate change, where the disaster cannot be prevented by means of current technology and infrastructure. Thus, the concept of DRM can include "resilience."

\section{Vison and Mission of CDRM}

The CDRM vision is to be a WFEO standing technical committee that professionally and internationally carries out activities to reduce natural disaster risks, from an engineering perspective. It must introduce and recommend useful practices and lessons, as well as engineering knowledge and innovative approaches to disaster damage reduction and the promotion of sustainable, sound development. The CDRM should contribute to all parts of the risk cycle, including identification, evaluation, the mitigation of, and the adaptation to disasters, which relate to all aspects of human life as well as to the economy, social activities, and the environment. The CDRM's priorities include developing comprehensive structural and non-structural measures to increase disaster resiliency and business continuity.

As a standing committee of WFEO, the CDRM aims to exchange, share, and transfer knowledge, technology, and expertise in order to reduce disaster risks. It also fosters research and investigations that relate to DRM, including examples of best practice, lessons, and their implementation. The CDRM will create advisory documents, policy papers, guidelines, reports, and booklets.

The CDRM will gather and disseminate DRM-related information that can help WFEO member countries, engineering societies, and leading engineers effectively mitigate risk and help societies adequately adapt to potential risks. The CDRM also helps to build the capacity of engineers working in these areas, by disseminating information through WFEO member country linkages to decision makers, governmental organizations, engineering societies, and leading engineers. The CDRM also coordinates international DRM efforts, and organizes conferences, presentations, and workshops related to DRM.

\section{Activities of CDRM}

The CDRM operates as a knowledge-hub that focuses on recognizing and promoting the worldwide contributions of engineers and practitioners, and on providing need-driven education and information to engineering communities around the world, especially in developing countries. The scientific analysis and advice on reducing risk (a combination of hazards and vulnerability) provided and distributed by the CDRM, provides an opportunity to improve societies and ways of living. In particular, understanding the scientific basis of a particular risk creates a crucial opportunity to make sustainable societal adjustments instead of unsustainable ones. Reducing disaster risk reduces damage that might otherwise impede continued economic development and environmental sustainability. Sharing best practice and lessons learned, as well as DRM networking and information-sharing, are two important operating principles of the CDRM. Natural disasters are categorized as either water-related disasters or earthquake-related disasters for further investigation and discussion in the CDRM.

Because there are a wide variety of disaster and risk management categories, diverse methods and technologies are needed to deal with them. During its initial two-year cycle of activities, the CDRM only considered water- and earthquake-related disasters. As a result of its good outcomes between 2009 and 2013, the committee was strongly advised to expand the scope of its activities to other disasters such as air pollution, volcanic explosions, forest fires, drought, desertification, and communicable diseases. Accordingly, the CDRM has upgraded its activities through the following three subcommittees: Water-related Disaster Risk Management (WDRM), Earthquake-related Disaster Risk Management (EQDRM), and Capacity Building for Natural Disaster Risk Management (CBNDRM), in order to deal with many different types of disasters.

\section{WFEO/CDRM and Sendai Framework}

In January 2015, the Tokyo Conference on International Study for Disaster Risk Reduction and Resilience was held in Tokyo. World leaders and top scientists participated in the conference prior to the Third UN World Conference on Disaster Risk Reduction to discuss and formulate how science and technology could help in disaster risk reduction, 
hence fostering sustainable development. Core members of CDRM participated in the conference and made substantive inputs from the viewpoint of engineering onto DRM. In particular, Dr. Komatsu, the chair of CDRM, was invited as a guest speaker and delivered a speech entitled "Implementation oriented technology for coping with natural disasters under the climate change."

In January 2016, the UNISDR Science and Technology Conference on the implementation of the Sendai Framework for Disaster Risk Reduction was held in Geneva and discussed how the science and technology community will best support the implementation of the Sendai Framework. Many engineers and engineering organizations actively participated in this conference and displayed how engineering supports the implementation of the Sendai Framework.

At the Asian Civil Engineering Coordinating Council (ACECC) 7th Civil Engineering Conference of Asian Region in August 2016, a Technical Committee 21 (TC21): Transdisciplinary Approach (TDA) for Building Societal Resilience to Disasters was launched to promote a trans-disciplinary approach for scientific knowledge-based decision-making for building societal resilience to disasters at national and local levels. As the Civil Engineering community is one of the most active areas to work with implementation of the Sendai Framework, CDRM has been working with TC21 to promote DRM activities of WFEO.

\section{The World Engineering Conference and Convention 2015, Kyoto}

WFEO holds a World Engineers' Convention (WEC) at intervals of four years. The 1st WEC took place in Germany in 2000, the 2nd in China in 2004, the 3rd in Brazil in 2008, and the 4th in Switzerland in 2011. The World Engineering Conference and Convention (WECC 2015), the 5th WEC, was held in Kyoto, Japan, from 29 November to 2 December 2015. This event showcased Japan as a nation built on scientific and technological innovation to achieve sustainable development in the 21 st century. WECC2015 also provided a forum for sharing information focused on innovations required to make sustainable development a reality and advances in fundamental technologies to achieve this vision. Adopting both local and global perspectives, WECC2015 made a productive contribution to worldwide peace and socioeconomic progress.

The overall conference theme of WECC2015 was "Engineering: Innovation and Society", and 10 tracks were convened in WECC2015. Among the 10 tracks, "Resilient Infrastructure for Society" is placed as the first track of WECC 2015. This track dealt with several aspects of disaster risk management from the viewpoint of engineering. In this track, the following items were presented and discussed:

\subsection{Reconstruction innovation}

1.2 Land/city conservation and disaster mitigation

1.3 Robot technology used at disaster sites and its operating systems

1.4 Strengthening national interests and creating new industries using big data

1.5 Creating a resilient economy

1.6 Resilience in the manufacturing and energy sectors.

In addition to these tracks, several prominent speakers delivered important lectures at WECC2015. The Crown Prince of Japan delivered an address. In His Imperial Highness's address he said "I believe that it is of great importance to hold discussions at WECC2015 as to how we can realise innovations and solve those challenges that face communities, such as energy issues as well as natural disasters and the safety of people" HIH expressed his expectation of engineering innovation in disaster risk reduction. In addition, Dr. Han Seung-soo, the UN Secretary-General's Special Envoy on Disaster Risk Reduction and Water, and Former Prime Minister of the Republic of Korea, delivered a lecture "Science and Technology for Water in a Carbon-Constrained World". The lecture was delivered from the perspectives of climate change and disaster management, and centered on the importance of science and technology in resolving these issues. Dr. Han explained that the importance of evidence-based policy decisions through science and technology had been being emphasized in major conferences in 2015, such as the Third UN World Conference on Disaster Risk Reduction in Sendai, the 7th World Water Forum in Daegu, Republic of Korea, and the UN Sustainable Development Summit in New York.

Dr. Yumio Ishii, the founding chair of CDRM, served as the Executive Committee Chair and made an enormous effort over many years in WECC2015 preparation (Fig. 2).

At WECC2015, CDRM held an international symposium on "River Technologies for Innovations and Social Systems" (hereafter, "River Technology") attended by over 100 participants. This symposium comprised opening and closing remarks, as well as three sessions, covering river/watershed disaster mitigation, environmental conservation, and a panel discussion to enhance worldwide information exchange on and public awareness of river technologies. Speakers had varying backgrounds related to disaster risk reduction (Fig. 3).

\section{Conclusion}

This paper explained what WFEO and WFEO's committee on disaster risk management (CDRM) are, and the activities of CDRM in achieving the goals of the Sendai Framework. Both The International Consortium on Landslides (ICL) and WFEO are international 
Fig. 2 Closing remarks-Dr. Ishii at WECC2015

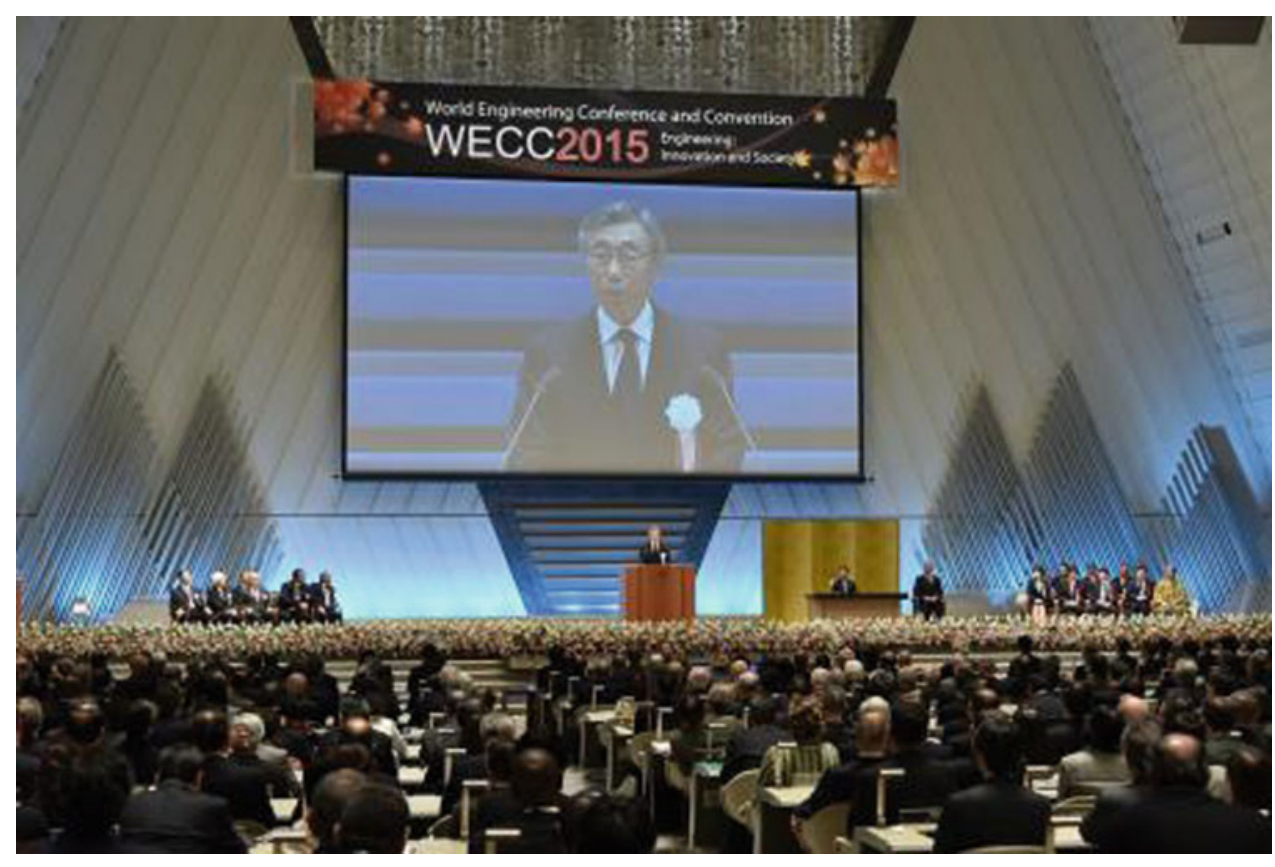

Fig. 3 CDRM symposium at WECC2015

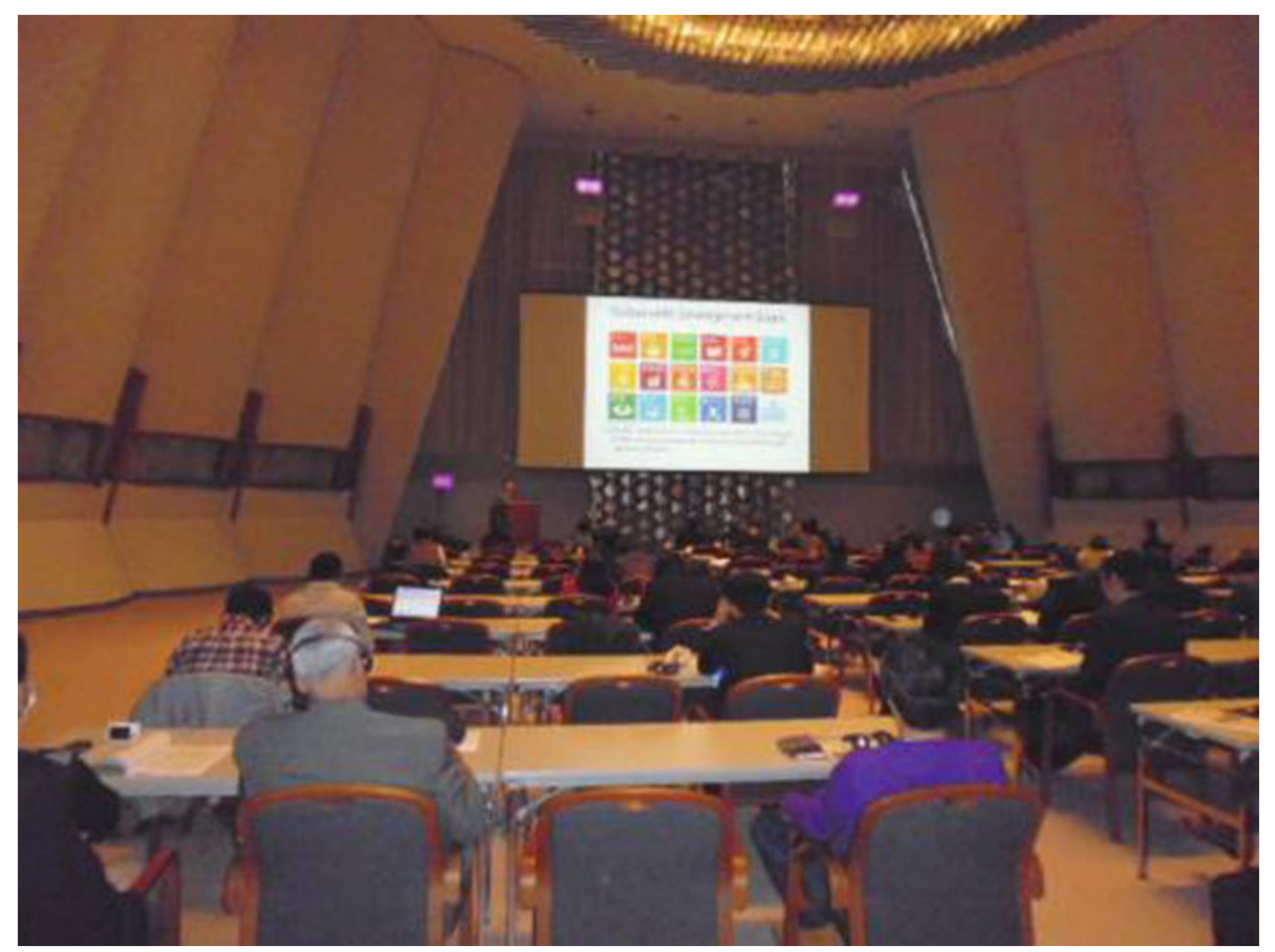

non-governmental and non-profit organizations that aim to utilize their member expertise to realize a better society, including reducing disaster risks. As stated in the paper, many important initiatives have been launched to support implementation of the Sendai Framework in the science and technology community. As ICL and CDRM have common objectives that utilize their scientific and engineering knowledge of DRR, close coordination of ICL and CDRM would make valuable inputs to implementing the Sendai Framework. 


\section{References}

WFEO, Homepage "About”. http://www.wfeo.org/about/

WFEO-CDRM, Homepage "CDRM Main Page". http://www.wfeo. org/stc_disaster_risk_management/
WFEO-CDRM, CDRM E-Newsletter-January 2016. http://www. wfeo.org/wp-content/uploads/stc-disaster_risk/CDRM_Newsletter_ 2016_Jan_No5_Final.pdf

The Organizing Committee of the World Engineering Conference and Convention, Report on the World Engineering Conference and Convention (WECC2015), March 2016. http://www.jfes.or.jp/ wecc2015/common/pdf/wecc2015_report_e.pdf
Open Access This chapter is licensed under the terms of the Creative Commons Attribution 4.0 International License (http:// creativecommons.org/licenses/by/4.0/), which permits use, sharing, adaptation, distribution and reproduction in any medium or format, as long as you give appropriate credit to the original author(s) and the source, provide a link to the Creative Commons license and indicate if changes were made.
The images or other third party material in this chapter are included in the chapter's Creative Commons license, unless indicated otherwise in a credit line to the material. If material is not included in the chapter's Creative Commons license and your intended use is not permitted by statutory regulation or exceeds the permitted use, you will need to obtain permission directly from the copyright holder. 